\title{
The State of Presence of Phosphor in Hamersley Pellet*
}

\section{By Kimitaka SATO** and Ken-ichi SUZUKI**}

\section{Synopsis}

There were significant differences among the 29 analytical values of phosphor in the Hamersley pellet obtained in nine laboratories by means of the JIS M8216 (1964) method; the values obtained were classified to either $0.050 \pm 0.005 \%$ or $0.019 \pm 0.004 \%$. As a result of the investigation of the cause of the difference, it was made clear that the analytical value of phosphor became nearly $0.050 \%$ when the acid insoluble residues were treated additionally with $\mathrm{K}_{2} \mathrm{~S}_{2} \mathrm{O}_{7}$ fusion, that is, about $60 \%$ of phosphor in the pellet remained in the acid insoluble residue.

In this paper, the process by which the phosphor in Hamersley iron ore was changed to be insoluble in inorganic acids during firing the pellet was investigated by using both chemical and X-ray analyses. It was shown that the phosphor in Hamersley iron ore became to be soluble into the $\alpha$ cristobalite formed at high temperature, and then formed stable glass to be insoluble in inorganic acids with the elements of $\mathrm{Al}, \mathrm{Ca}$, and $\mathrm{Fe} . \mathcal{N}_{0}$ other samples except the Hamersley pellet gave an anomalous value.

\section{Introduction}

The phosphor in iron ores is usually analysed by the method $^{1)}$ of the Japanese Industrial Standards (JIS), which is also used for analysis of phosphor in pellets employed favourablly as one of raw materials for making pig iron recently. The analytical operation of phosphor is illustrated in Fig. 1. In the analysis of pellet as well as iron ore, however, phosphor in the

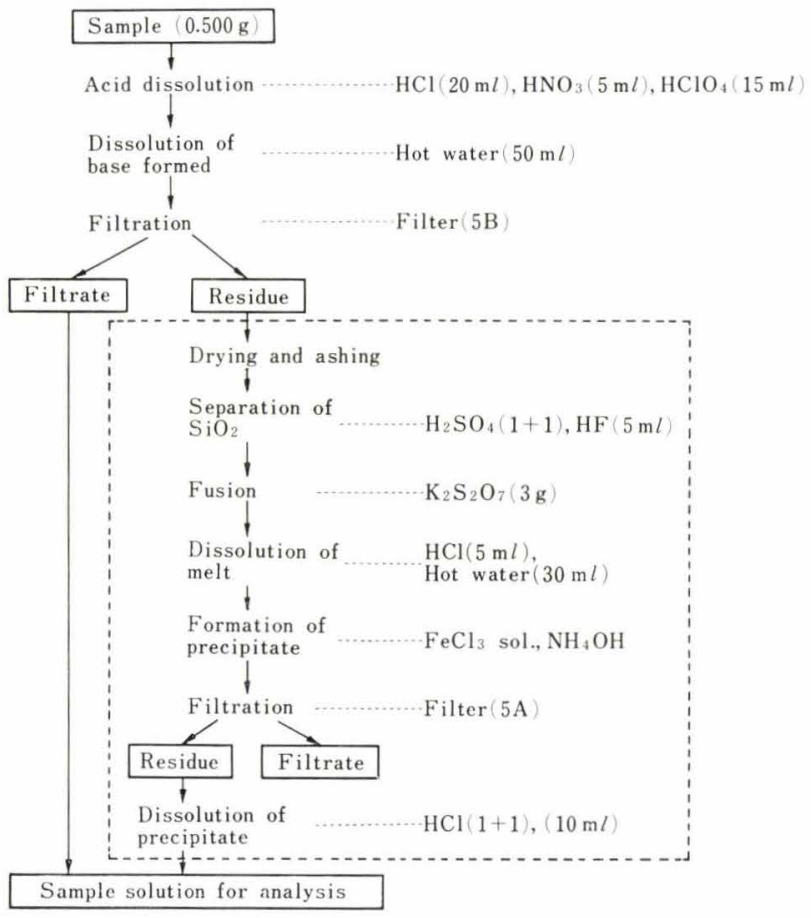

Fig. 1. Acid dissolution method of sample in the analysis of phosphor in iron ore (JIS M 8216-1964) acid insoluble residues were often neglected empirically after acid dissolution as shown in Fig. 1.

In the analysis of pellets produced from Hamersley iron ores, it was found by chance that the analytical values of phosphor were significantly different among some analytical laboratories; the 29 analytical values in 9 analytical laboratories were classified to two groups of $0.050 \pm 0.005 \%$ and $0.019 \pm 0.004 \%{ }^{2}{ }^{2}$ As a result of study about the reason, it has become apparent that the analytical values of phosphor were about $0.050 \%$ when the residues were fused additionally with $\mathrm{K}_{2} \mathrm{~S}_{2} \mathrm{O}_{7}$ after acid dissolution as shown inside dotted square in Fig. 1 and about $60 \%$ of content of the phosphor remained in the acid insoluble residues.

We were interested in the behaviour of phosphor in Hamersley pellet from the idea that some valuable informations must be obtained for the improvement of analytical operation or the setting of pelletizing conditions, if these problems were made clear. Then, study was made clear the process for the phosphor to become acid soluble during the production of pellets, by use of chemical and X-ray analyses.

\section{Experimental Procedure}

\section{Specimens}

Six kinds of Hamersley iron ores were used as masses (their weights: 5 to $50 \mathrm{~g}$ ), which were taken from the ore yard of Yawata Works, and six kinds of Hamersley pellets which were also used, had different apparent specific gravities ${ }^{3)}$ and were collected as Kimitsu Works of our corporation. The chemical compositions of the Hamersley iron ores and pellets

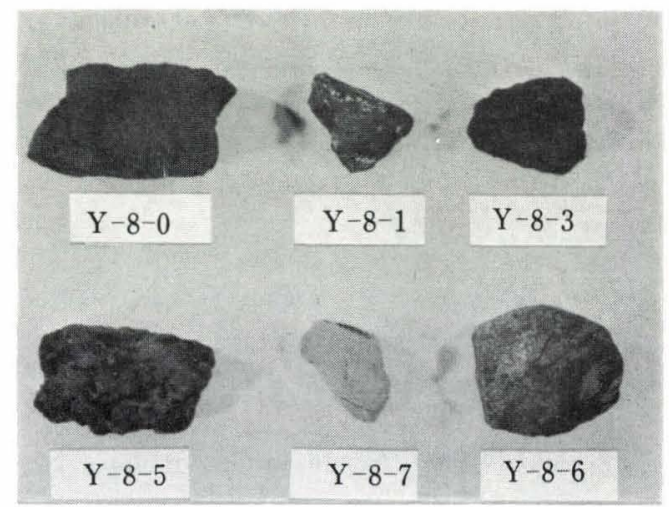

Photo. 1. Outward appearance of Hamersley iron ores used in this investigation

* Originally published in Tetsu-to-Hagané, 59 (1973), 493, in Japanese. English version received December 19, 1973.

** Fundamental Research Laboratories, Nippon Steel Corp., Ida, Nakahara-ku, Kawasaki 211. 
Table 1. Chemical composition of Hamersley iron ores and pellets

\begin{tabular}{|c|c|c|c|c|c|c|c|c|}
\hline \multirow{2}{*}{ Sample } & \multirow{2}{*}{ Symbol } & \multirow{2}{*}{$\begin{array}{l}\text { Apparent } \\
\text { specific } \\
\text { gravity* }\end{array}$} & \multicolumn{6}{|c|}{ Analytical values $(\%)$} \\
\hline & & & Total $\mathrm{Fe}$ & $\mathrm{SiO}_{2}$ & $\mathrm{Al}_{2} \mathrm{O}_{3}$ & $\mathrm{CaO}$ & Sol. $\mathrm{P} * *$ & Insol. $\mathrm{P}^{* * * *}$ \\
\hline \multirow{6}{*}{ Iron ores } & $\mathrm{Y}-8-0$ & & 69.37 & 0.65 & 0.26 & $<0.1$ & 0.016 & $<0.003$ \\
\hline & $Y-8-1$ & & 64.48 & 3.59 & 2.51 & $<0.1$ & 0.046 & 0.004 \\
\hline & $Y-8-3$ & & 68.70 & 1.18 & 0.47 & $<0.1$ & 0.016 & 0.006 \\
\hline & Y-8-5 & & 46.68 & 28.21 & 1.02 & $<0.1$ & 0.036 & 0.005 \\
\hline & $Y-8-6$ & & 23.80 & 29.35 & 24.0 & $<0.3$ & 0.044 & $<0.003$ \\
\hline & $Y-8-7$ & & 9.88 & 53.90 & 11.6 & $<0.3$ & 0.074 & $<0.003$ \\
\hline \multirow{6}{*}{ Pellets } & HK 2-1 & 3.25 & 64.24 & 5.03 & 2.43 & 0.31 & 0.034 & 0.016 \\
\hline & HK 2-2 & 3.40 & 64.69 & 4.21 & 2.63 & 0.26 & 0.018 & 0.031 \\
\hline & HK 2-3 & 3.55 & 64.85 & 4.27 & 2.42 & 0.21 & 0.021 & 0.036 \\
\hline & HK 2-4 & 3.70 & 64.35 & 4.08 & 2.48 & 0.57 & 0.018 & 0.032 \\
\hline & HK 2-5 & 3.85 & 64.60 & 4.16 & 2.42 & 0.43 & 0.014 & 0.034 \\
\hline & HK 2-6 & 3.95 & 64.32 & 4.26 & 2.63 & 0.53 & 0.018 & 0.031 \\
\hline
\end{tabular}

* $\quad$ Reference (3)

** Sol. P: phosphor soluble with inorganic acid

*** Insol. P: phosphor insoluble with inorganic acid

are shown in Table 1 and the outward appearances of the Hamersley iron ores are illustrated in Photo. 1.

\section{Measurements}

The compositions of the elements contained in the acid insoluble residues were analysed qualitatively by using a Jarrel-Ash $3.4 \mathrm{~m}$ grating emission spectrograph. The iron ores, pellets and their acid insoluble residues were also identified with X-ray diffraction by a "Geigerflex D-II" manufactured by Rigaku Denki Co., Ltd. The behaviour of each element in the acid insoluble residues was investigated with characteristic X-ray images by an ARL electron probe microanalyzer.

\section{Experimental Results and Discussion}

The 29 analytical values of phosphor in Hamersley pellet at nine analytical laboratories were classified as summerized in Table 2; it was found that the lower values were only about $40 \%$ of the higher ones. As a result of the investigation from various points of view, it was made clear that about $60 \%$ of phosphor in the specimen was contained in the acid insoluble residues and was not treated for complete recovery in most analytical laboratories. Therefore, the reason why the abnormal values are obtained can be evidently explained, if the difference among analytical values is due to the phosphor in the acid insoluble residues. From the reasons above mentioned, the following study was carried out to make clear the process which about $60 \%$ of the phosphor became acid insoluble by using some chemical and X-ray analyses.

\section{Chemical Composition of Specimens}

The analytical values of acid soluble and insoluble phosphor in Hamersley iron ores and their pellets are shown in Table 1, together with the analytical results of main chemical components in them. As being compared with their values, the masses of ores containing some gangues such as sillica and alumina ( $\mathrm{Y}-8-5$ to
Table 2. Analytical results of phosphor in Hamersley pellet

\begin{tabular}{|c|c|c|}
\hline & A & $\mathrm{B}$ \\
\hline $\begin{array}{l}\text { Number of analytical } \\
\text { laboratories* }\end{array}$ & 2 & 8 \\
\hline $\begin{array}{l}\text { Number of analytical } \\
\text { values }\end{array}$ & 8 & 21 \\
\hline Analytical value & $0.050 \pm 0.005 \%$ & $0.019 \pm 0.004 \%$ \\
\hline
\end{tabular}

Y-8-7) are present in Hamersley iron ores and also contain much amounts of phosphor, most of which is insoluble in acid. The fact must be worth noting.

On the other hand, acid insoluble phosphor is about twice as much as acid soluble one in the pellets; it shows the opposite tendency for the iron ores. However, only the HK 2-1 pellet whose apparent specific gravity is much smaller than the others is exceptional and contains much acid soluble phosphor.

\section{Composition of Acid Insoluble Residues}

The Hamersley iron ores and their pellets were decomposed in hydrochloric, nitric and perchloric acids on heating for about $2 \mathrm{hr}$ according to the JIS method $^{1)}$ and the acid insoluble residues obtained were collected on a microfilter of hole diameter of $0.5 \mu \mathrm{m}$. After drying them, the ratio of residues for the specimens were determined by weighing. The qualitative compositions of the residues were also analysed by means of an emission spectrophotographic method.

From their results as shown in Table 3, it was found that most of residues were composed of silicon, while there were much aluminium and calcium in the residues of the pellets better than in the residues of the iron ores. Phosphor was notably detected in the residues of HK 2-3 and HK 2-6. From these facts, it was estimated that much phosphor must be contained in the residues. 
Table 3. Analytical results of residues extracted from Hamersley iron ores and pellets

\begin{tabular}{|c|c|c|c|c|c|c|c|c|c|c|c|c|c|c|}
\hline \multirow{2}{*}{ Sample } & \multirow{2}{*}{$\begin{array}{l}\text { Ratio of } \\
\text { residue } \\
(\%)\end{array}$} & \multirow{2}{*}{$\begin{array}{l}\text { Insoluble } \\
\mathrm{P}(\%) \\
\text { found in } \\
\text { residue }\end{array}$} & \multicolumn{9}{|c|}{ Emission spectrochemical analysis of residue } & \multicolumn{3}{|c|}{ X-ray diffraction analysis* } \\
\hline & & & $\mathrm{Na}$ & $\mathrm{Mg}$ & $\mathrm{Al}$ & $\mathrm{Si}$ & $\mathrm{P}$ & $\mathrm{Ca}$ & $\mathrm{Ti}$ & $\mathrm{Mn}$ & $\mathrm{Fe}$ & Sample & Residue & $\begin{array}{l}\text { Residue after } \\
\text { heating** }\end{array}$ \\
\hline $\mathrm{Y}-8-0$ & 0.75 & $<0.4$ & \pm & \pm & + & HWl & - & \pm & + & \pm & m & $H$ & $Q, H$ & \\
\hline $\mathrm{Y}-8-1$ & 3.65 & 0.11 & \pm & \pm & H & H⿻l一t & - & \pm & + & \pm & H & $H$ & $H$ & \\
\hline $\mathrm{Y}-8-3$ & 1.23 & 0.49 & + & \pm & $H$ & HII! & - & \pm & + & \pm & H & $H$ & $Q, C$ & \\
\hline $\mathrm{Y}-8-5$ & 28.6 & 0.02 & \pm & \pm & \pm & H\#H & - & \pm & $H$ & \pm & H & $H, Q$ & $Q$ & $Q, C$ \\
\hline$Y-8-6$ & 34.7 & $<0.01$ & \pm & \pm & m & mI & - & \pm & $H$ & \pm & H & $H, D, G$ & $D$ & $C, M$ \\
\hline$Y-8-7$ & 56.2 & $<0.01$ & \pm & \pm & \pm & HII & - & \pm & H & \pm & + & $Q, D$ & $Q$ & $C, Q$ \\
\hline HK 2-1 & 6.82 & 0.23 & \pm & \pm & HI & HWI & - & $H$ & + & + & H & $H$ & $C, Q, H$ & \\
\hline HK $2-3$ & 5.52 & 0.65 & \pm & + & HI & HIt & + & H & + & H & m & $H$ & $C$ & \\
\hline HK 2-6 & 6.40 & 0.49 & $H$ & + & HII & HII & + & H & + & H & H & $H$ & $C, Q, H$ & \\
\hline
\end{tabular}

* $H$ : hematite, $\alpha-\mathrm{Fe}_{2} \mathrm{O}_{3} \quad G$ : goethite, $\alpha$-FeOOH $\quad Q$ : quartz, $\alpha-\mathrm{SiO}_{2} \quad C$ : cristobalite, $\alpha-\mathrm{SiO}_{2} \quad M: \quad \mathrm{mullite}_{2}, 3 \mathrm{Al}_{2} \mathrm{O}_{3} \cdot 2 \mathrm{SiO}_{2}$ $D$ : kaoline (dickite), $\mathrm{Al}_{2} \mathrm{O}_{3} \cdot 2 \mathrm{SiO}_{2} \cdot 2 \mathrm{H}_{2} \mathrm{O}$

** Residues were heated up to $1330^{\circ} \mathrm{C}$ with heating rate of $10^{\circ} \mathrm{C} / \mathrm{min}$ and were cooled in a oven.
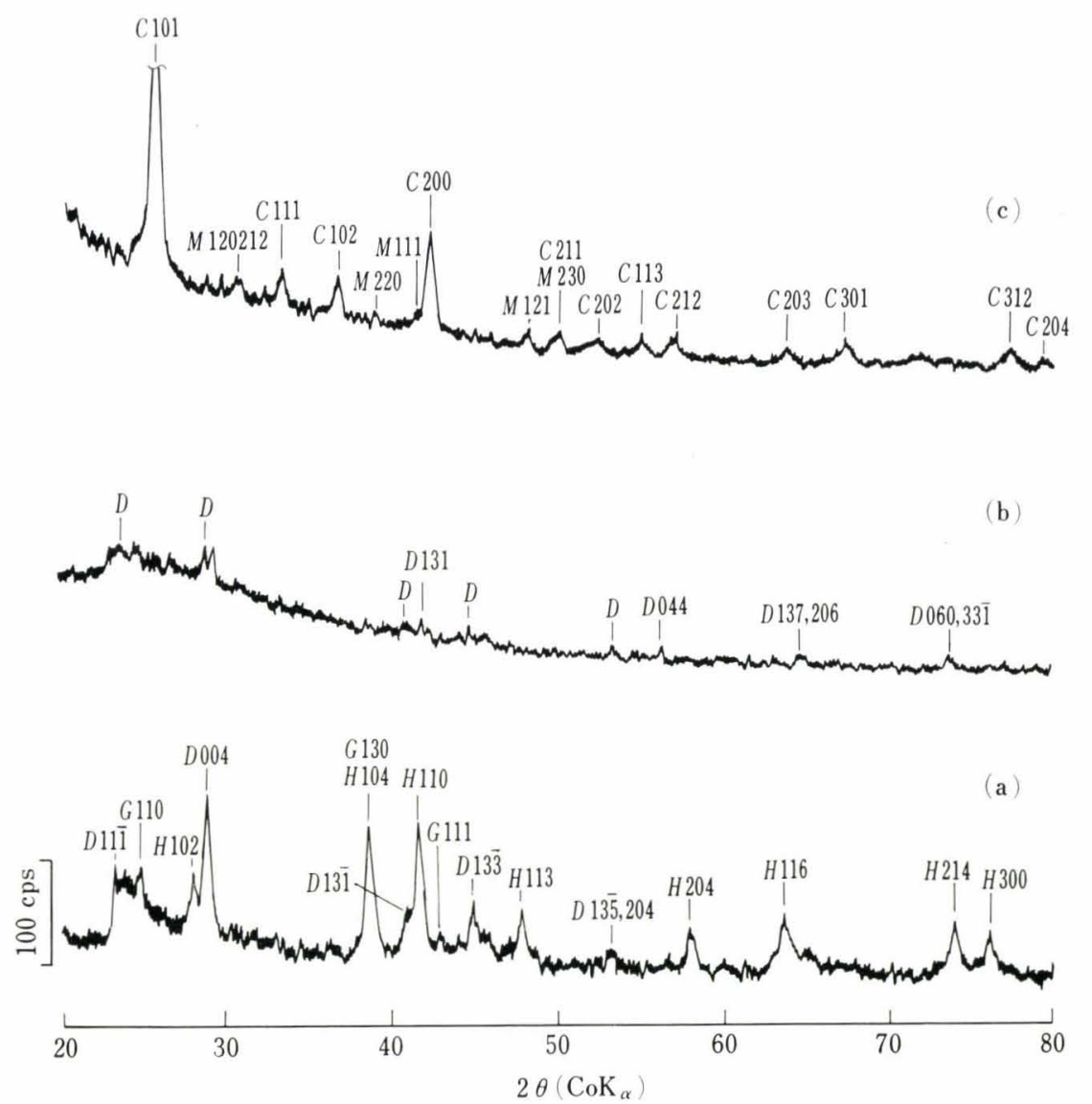

Fig. 2.

$\mathrm{X}$-ray diffraction patterns of Hamersley iron ore (Y-8-5) (a) Original iron ore, (b) Residue insoluble with inorganic acid, (c) Residue after heating. The measurements were carried out at the voltage of $20 \mathrm{kV}$ and the current of $9 \mathrm{~mA}$. Symbol: see Table 3

\section{Discussion by $X$-ray Diffractometric Analysis}

The mineralogical structure of Hamersley iron ores, pellets and their acid insoluble residues were identified by analysis of X-ray diffraction patterns. The results of the identification are shown in Table 3 and some examples of the X-ray diffraction patterns are illustrated in Figs. 2 and 3.

In general, $\alpha$-quartz $\left(\alpha-\mathrm{SiO}_{2}\right)$ and kaoline (dickite; $\left.\mathrm{Al}_{2} \mathrm{O}_{3} \cdot 2 \mathrm{SiO}_{2} \cdot 2 \mathrm{H}_{2} \mathrm{O}\right)$ were identified from the iron ores containing much gangues and their acid insoluble residues. On the other hand, any impurity components except hematite $\left(\alpha-\mathrm{Fe}_{2} \mathrm{O}_{3}\right)$ were not detected from the pellets, while crystalline $\alpha$-crystobalite $\left(\alpha-\mathrm{SiO}_{2}\right)$ was identified in addition to $\alpha$-quartz $\left(\alpha-\mathrm{SiO}_{2}\right)$ from the acid insoluble residues of the pellets. In this manner it was recognized that there was clear difference between the residues of iron ores and pellets.

In order to make clear the formation process of $\alpha$ crystobalite $\left(\alpha-\mathrm{SiO}_{2}\right)$, the residues of the iron ores containing much gangues, 100 to $200 \mathrm{mg}$, was collected in the small cell of platinum and was then heated up to $1330^{\circ} \mathrm{C}$ with heating rate of $10^{\circ} \mathrm{C} / \mathrm{min}$ in air. The residues after heating were cooled in an oven and were identified by an X-ray diffraction. As the results, $\alpha$-crystobalite was identified in addition to $\alpha$-quartz 


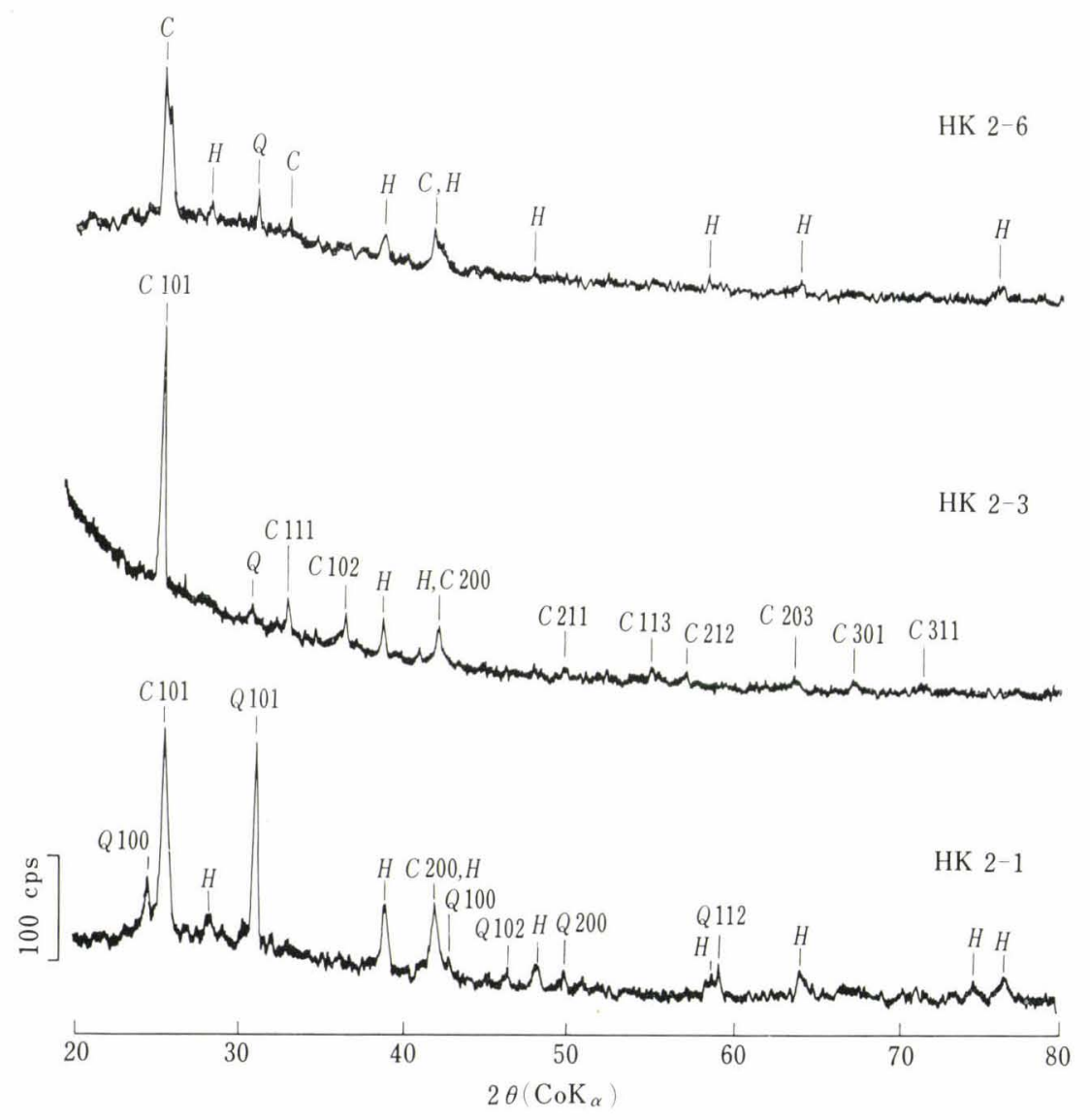

Fig. 3.

$\mathrm{X}$-ray diffraction patterns of residues insoluble with inorganic acid in Hamersley pellets. The measurement were carried out at the voltage of $20 \mathrm{kV}$ and the current of $9 \mathrm{~mA}$. Symbol: see Table 3

which had been present in the original residue. In particular, mullite $\left(3 \mathrm{Al}_{2} \mathrm{O}_{3} \cdot 2 \mathrm{SiO}_{2}\right)$ was then identified together with $\alpha$-crystobalite. But, kaoline cannot be detected from the residues after heating of the iron ore Y-8-6 containing much kaolines. Accordingly, the phenomenon can be explained to happen since kaoline decomposes to transform into $\alpha$-crystobalite and mullite.

\section{Electron Probe Microanalysis of Acid Insoluble Residues}

The acid insoluble residues of pellets were dispersed on the plate of beryllium ${ }^{4}$ finished up to a mirror-like face and the correspondence of characteristic X-ray images was investigated for the particles of residues by an electron probe microanalyzer. As known from the X-ray images illustrated in Photo. 2, it was found that aluminium, small amounts of calcium and iron coexisted together with silicon which was the main component in the particles containing phosphor in the residues.

\section{Discussion for Pelletizing Process}

On the basis of the above mentioned results, we must discuss on the behaviour of phosphor in the process which Hamersley iron ores are fired into pellets.

According to the results of identification by X-ray diffraction, $\alpha$-quartz and kaoline are crystalline minerals containing silicon as the main components in Hamersley iron ores, while $\alpha$-quartz and $\alpha$-crystobalite are contained in Hamersley pellets. Kaoline is transformed into mullite at the temperature higher than about $1000^{\circ} \mathrm{C}$ and this tendency proceeds with the increasing of temperature. The silica released with the reaction is also transformed into a crystobalite. ${ }^{5)}$ The crystobalite, however, is unstable $\beta$-form, so it degenerates to glass together with the impurity components such as aluminium, calcium and iron. In the iron ores, the phase of glass is generally soluble in acid, while acid insoluble phase is also present in the glass formed in the pellets. It is explained that the phosphor is dissolved into the acid insoluble glass formed at high temperature, from the analytical results by an electron probe microanalyzer.

It can be easily estimated that the ratio which kaoline forms glass and which phosphor is dissolved into glass are different according to the firing condition of pellets, and are determined due to the temperature and time of heating. Kondo et al. ${ }^{3)}$ reported that the quality of pellets was different due to the firing condition and can be determined by measuring the distribution of apparent specific gravity. In case of Hamersley pellets taken at the Yawata, Hirohata and Kimitsu Works, the averages of apparent specific gravity were from 3.6 to 3.8 and those of less than 3.4 were below several percentage. According to the present results discussed, only the HK 2-1 contains more amount of acid soluble phosphor than that of acid insoluble one and the apparent specific gravity of the pellet is only 3.25. Accordingly, it may be said that the firing of the HK 2-1 pellet is insufficient. We can easily understand the reason why the pellet of HK 2-1 has low apparent specific gravity, on the basis of the consideration that only small amount of phosphor dissolve into glass and more phosphor is acid-soluble since kaolines do not sufficiently form glass. Moreover, the ratio of acid insoluble phosphor to acid 

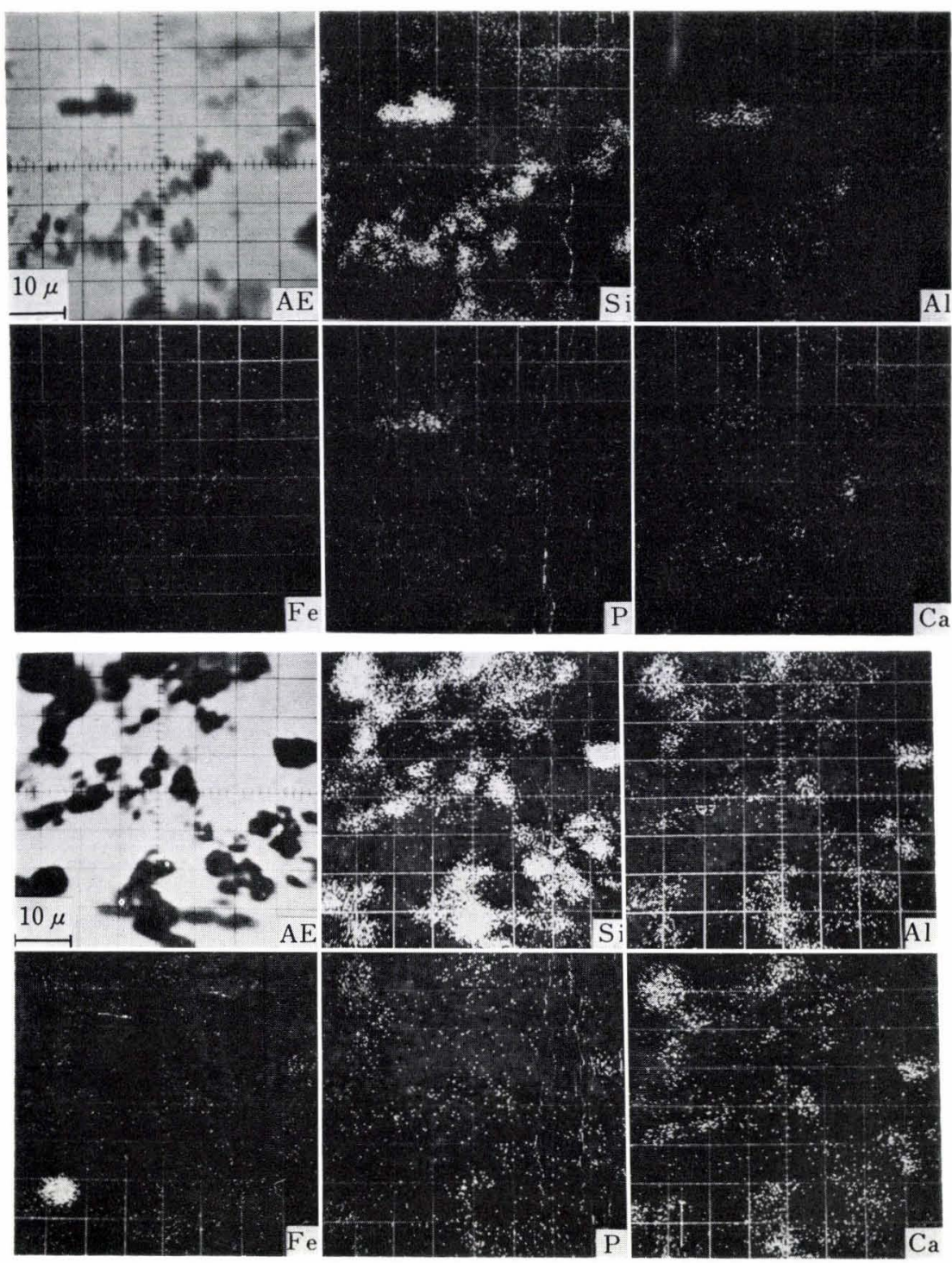

(a) $\mathrm{HK} 2-3$

(b) HK 2-6

Photo. 2.

EPMA scanning images of residues extracted from Hamersley pellet soluble one are from 1.7 to 2.4 , when the apparent specific gravities of the fired pellets are the ranges of 3.40 to 3.95. The reason is explained by that the kaoline changes sufficiently to glass, in which the solid solution containing phosphor reaches to equilibrium.

From the above discussion, the phenomenon which abnormal values are obtained in the analysis of phosphor in Hamersley pellets takes place by the reason that more components of gangues are present in Hamersley iron ores. Such pellet is specific example which we have not be experienced. Accordingly, in the analyses of iron ores and pellets, the components of gangues must be taken into consideration despite desired components of analysis and the solid solutions such as acid insoluble glass formed at high temperature must be always treated for complete recovery.

From the results of this investigation, it was found that the degree of firing of Hamersley pellets can be evaluated not only by an apparent specific gravity but also by acid soluble or acid insoluble phosphor value.

\section{Conclusions}

In the present paper, the investigation was made on the reason why the analytical values of phosphor in
Hamersley pellets were classified to two groups which were $0.019 \pm 0.004 \%$ and $0.050 \pm 0.005 \%$ in relation to the behaviour of phosphor during the firing of the pellets. The results obtained are summerized as follows :

(1) There are the masses of ores containing gangues such as silica and alumina in Hamersley iron ores, in which phosphor is rich and is almost acidsoluble.

(2) In Hamersley pellets, the analytical value of acid insoluble phosphor is two times as much as the one of acid soluble except the pellets having smaller apparent specific gravity.

(3) According to a qualitative emission spectrographic analysis, most of acid insoluble residues of the iron ores is composed of silicon, while phosphor in the pellets is present together with aluminium, calcium, silicon and iron.

(4) $\alpha$-quartz and kaoline (dickite; $\mathrm{Al}_{2} \mathrm{O}_{3} \cdot 2 \mathrm{SiO}_{2}$. $2 \mathrm{H}_{2} \mathrm{O}$ ) were found in the iron ores containing rich gangues, while hematite was found in the pellets by an X-ray diffraction. However, as $\alpha$-crystobalite was also present with $\alpha$-quartz in the acid insoluble residues of the pellets, therefore it was clear that the differences between the iron ores and the pellets are 
present.

(5) According to an electron probe microanalysis of acid insoluble residues, it was recognized that phosphor existed together with aluminium, calcium and iron besides silicon which is present as the main component.

(6) Consequently, it is explained that phosphor in Hamersley iron ore forms a solid solution in $\alpha$-crystobalite formed at high temperature such as firing the pellets, which becomes stable and acid-insoluble glass containing aluminium, calcium, and iron. From the reason mentioned above, in Hamersley pellets, lower analytical value is obtained by the more portion of phosphor (nearly $60 \%$ of total content) remaining in the residues, if the acid insoluble residues are not treated for complete recovery in the process of the analytical operation. This is a very unique phenomenon encountered only in case of Hamersley pellets.

\section{Acknowledgements}

The authors would like to thank Dr. M. Sasaki and Mr. T. Nakazawa for providing the specimens and valuable discussion. They are also indebted to the analysts of Hirohata Works of their Corporation for proposing the problem.

\section{REFERENCES}

1) Japanese Industrial Standards, JIS M8216 (1964).

2) The data from the technical meeting of analysis in Nippon Steel Corporation (1970)

3) S. Kondo, M. Sasaki, T. Nakazawa, and K. Ito: Tetsu-toHagané, 56 (1970), S366

4) K. Sato and S. Funaki: Japan Analyst, 21 (1972), 1017; Advances in X-Ray Analysis (Japan), IV, Kagaku-Gijutsusha, Tokyo, (1972), 161.

5) B. Yoshiki: Mineral Technology (Kōbutsu Kōgaku), Gihodo Ltd., Tokyo, (1959), 427. 